\title{
Conversion of limestone-limestone mining waste by impregnation with polysulfide solutions
}

\author{
I.A. Massalimov ${ }^{1 *}$ (D) B.I. Massalimov² (iD, B.S. Akhmetshin'1 (iD, F.K. Urakaev³ (iD, M.M. Burkitbaev ${ }^{4}$ (iD \\ ${ }^{1}$ Bashkir State University, Ufa, Republic of Bashkortostan, Russia; \\ 2 Physics Institute. P.N. Lebedev RAS, Moscow, Russia; \\ ${ }^{3}$ Institute of Geology and Mineralogy Sobolev SB RAS, Novosibirsk, Russia. \\ ${ }^{4}$ Kazakh National University, Almaty, Kazakhstan \\ * Corresponding author: e-mail: ismail_mass@mail.ru \\ (c) Authors, 2020
}

\begin{abstract}
The data of studies on the effectiveness of impregnating Aquastat waste generated as a result of the development of limestone-shell rock deposits are presented. As a result of sand impregnation, the water absorption coefficient as a result underwent a significant decrease from 7 to 17 times, while the water absorption coefficient decreases from $32.5 \%$ for the initial to $1.9 \%$ impregnated. Even treatment with low concentrated $\left(\rho=1.17 \mathrm{~g} / \mathrm{cm}^{3}\right)$ calcium polysulfide solution made the water absorption coefficient to decrease to a value of $4.5 \%$. As a result of impregnation of crushed stone from limestone-limestone with a solution of calcium polysulfide, the water absorption coefficient decreases from $25.0 \%$ for untreated to $5.2 \%$ for treated, and the decrease in the coefficient of water absorption is greater for concentrated solutions. It was found that a solution density of $1.24 \mathrm{~g} / \mathrm{cm}^{3}$ is sufficient to reduce the water absorption coefficient to a value of $5.2 \%$, the same as for a density value of $1.35 \mathrm{~g} / \mathrm{cm}^{3}$. Comparison of the results of impregnation with «Aquastat» solution and sulfur melt showed that as a result of treatment with sulfur melt, the water absorption coefficient decreases by 13.3 and strength increases by 2 times, and as a result of impregnation with «Aquastat» solution decreases by $4.62 \%$, strength increases by 1.35 times. Despite the high efficiency of sulfur melt processing, such treatment has drawbacks associated with the use of autoclave technology and high temperatures.

The results of the modification of sand and crushed stone from shell rock by impregnating it with the «Aquastat» solution, a significant decrease in the water absorption parameter, an increase in compressive strength, revealed the possibility of using impregnated crushed stone as the layer material lying at the base of the road structures of local roads in the form of crushed stone and sand instead of the more expensive imported crushed stone.
\end{abstract}

KEYWORDS: limestone, shell lime, sulfur, impregnation, strength, waste, hydrophobization, polysulfide.

ACKNOWLEDGMENTS: The authors thank the PCF of the Republic of Kazakhstan and the Skolkovo Foundation for their support. FOR CITATION: Massalimov I.A., Massalimov B.I., Akhmetshin B.S., Urakaev F.K., Burkitbaev M.M. Conversion of limestone-limestone mining waste by impregnation with polysulfide solutions. Nanotechnologies in Construction. 2020, Vol. 12, no. 2, pp. 77-83. DOI: 10.15828/2075-8545-2020-12-2-77-83.

\section{INTRODUCTION}

So hell rock is a type of porous limestone, consisting of mollusks shells, sand and clay that pressed for thousands of years under high pressure and temperatures. The material is given to man by nature and is completely ready for use. The large distribution of limestone makes it possible to extract it in various regions of the world [1-6]. The majority of large deposits are confined to the western part of Russia. There are quarries for the extraction of this stone in the Voronezh, Tula, Belgorod, Arkhangelsk and
Vologda regions. Limestone is also mined in the North Caucasus, the Urals, in certain regions of Siberia and in the Moscow region. The most profitable deposits are located in the central regions of the European territory of Russia. The Chelyabinsk region has the largest reserves in the Urals, and in Siberia: Novosibirsk, Kemerovo regions and the Krasnoyarsk Territory. There were explored 122 limestone deposits in Kazakhstan, suitable for lime production, and the reserves of these deposits are very extensive. Kazakhstan can be considered as a Klondike for the production of various types of lime and has an 
excellent regional location for the supply of limestone and finished lime to neighboring regions and countries of the Customs Union.

Shell rock mined in quarries often has a widely developed capillary system in its microstructure, filled with air. Due to this fact, the stone has high noise-canceling properties and minimal thermal conductivity, which allows to save on expensive energy resources. For the extraction of shell rock, explosive, excavator, and combine methods are used, and a lot of waste is generated in the form of crushed stone and small crumbs, which can be used during construction and road filling. Despite the widespread use of limestone-shell rock in construction, it is necessary to note some of its shortcomings, which can reduce the operational characteristics and durability of building materials. This material is hygroscopic, has a significant porosity of $22-50 \%$, gradually dissolves in water, the dissolution rate increases when exposed to groundwater and precipitation saturated with acidic compounds, which determines its relatively low frost resistance (frost resistance grade F15-F35) and a decrease in strength upon saturation with water, the softening coefficient is $0.6-0.9$. Thus, the issues of protection of building materials from limestone-shell rock from moisture and increasing their durability are relevant [7-9].

One of the simplest and most technologically advanced methods for solving the problem of improving operational properties and increasing durability is impregnation with polysulfide solutions. So, an impregnation was carried out for shell rock, providing deep penetration of the polysulfide solution into the material [10]. As a result, it was shown that the impregnation of limestone-shell rock with polysulfide solutions improves the operational properties and increases the durability of wall, facing and road building materials based on it, exposed to atmospheric influences.

It should also be noted that in many quarries in Russia and the Republic of Kazakhstan, as a result of the barbaric mining of limestone in order to use it as a facing material, a significant amount of limestone has accumulated in the form of sand of various fractions, the improvement of its operational characteristics along with crushed stone would make it possible to obtain a very important building material sand for road construction. The positive results of the use of polysulfide solutions can serve as an incentive for the processing of waste from limestone quarries of limestone (in the form of sand and gravel), which in the natural state do not possess the set of physicochemical properties necessary for their use in road and industrial construction [11-13]. Thereby, an experiment was conducted on the impregnation of limestone sand and crushed stone in order to reduce the water absorption parameter, using the polysulfide solution treatment technique [14-17].

\section{MAIN PART}

To modify the properties, we used sand as screening of limestone-shell rock of the Beineu deposit of the Mangistau region of a fraction of $2.5 \mathrm{~mm}$, which is formed when crushed stone is obtained from limestone-shell rock. The indicated fraction of sand was impregnated with solutions of calcium polysulfide of various densities, Fig. 1 shows images of sand of the initial la and impregnated with a solution of calcium polysulfide with a density of $1.24 \mathrm{~g} / \mathrm{cm}^{3}$ for 1 hour.

Fig. 1 shows that the impregnation leads to a noticeable change in the color of sand, and studies have shown that the impregnation of sand led to a noticeable

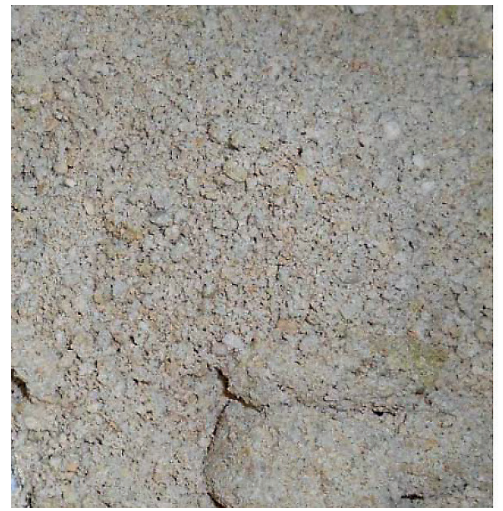

a

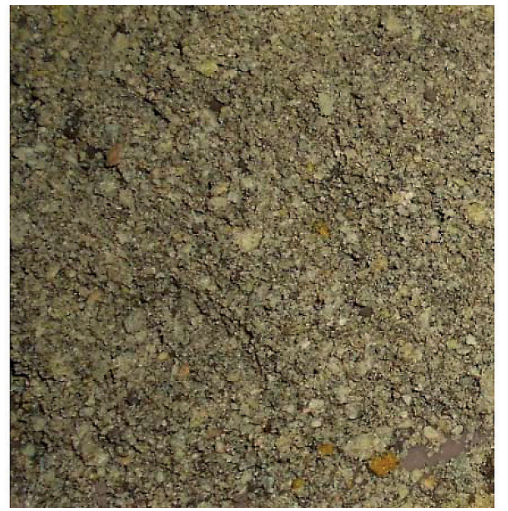

$\mathrm{b}$

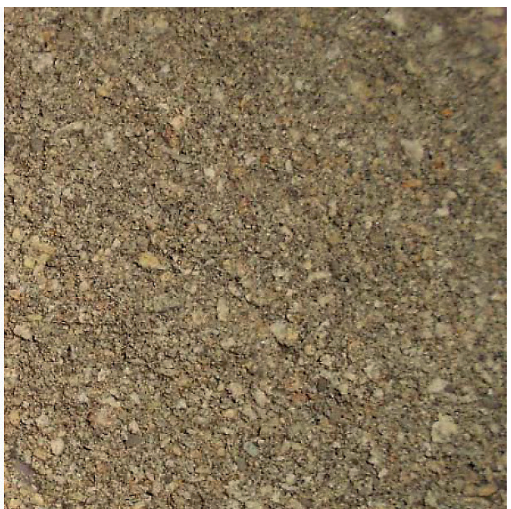

$\mathrm{c}$

Fig. 1. Sand fraction $2.5 \mathrm{~mm}$ from the screening of limestone-shell rock, $\mathbf{a}$ - the original, $\mathbf{b}$ - impregnated with a solution of «Aquastat» with a density of $1.24 \mathrm{~g} / \mathrm{cm}^{3}$ for 30 minutes; $\mathrm{c}$ - impregnated with the Aquastat solution with a density of $1.24 \mathrm{~g} / \mathrm{cm}^{3}$ for 60 minutes 


\section{Table 1}

Physico-mechanical properties of sand from limestone-shell rock, fraction $2.5 \mathrm{~mm}$, impregnated in solutions of calcium polysulfide of various densities

\begin{tabular}{|c|c|c|c|c|}
\hline № & $\begin{array}{c}\text { The density } \\
\text { of the solution, } \mathbf{g} / \mathbf{c m}^{\mathbf{3}}\end{array}$ & $\begin{array}{c}\text { The degree of prop, } \\
\mathbf{\%} \mathbf{1} \mathbf{~ h}\end{array}$ & Bulk density, $\mathbf{g} / \mathbf{c m}^{\mathbf{3}}$ & $\begin{array}{c}\text { The coefficient of water } \\
\text { absorption,\% }\end{array}$ \\
\hline original & - & - & 0.551 & 32.5 \\
\hline 1 & 1.16 & 14.25 & 0.701 & 4.5 \\
\hline 2 & 1.17 & 17.17 & 0.679 & 3.5 \\
\hline 3 & 1.19 & 17.33 & 0.678 & 2.2 \\
\hline 1 & 1.20 & 17.68 & 0.683 & 2.6 \\
\hline 5 & 1.22 & 19.27 & 0.697 & 2.5 \\
\hline 4 & 1.24 & 21.69 & 0.693 & 2.0 \\
\hline 6 & 1.35 & 22.64 & 0.704 & 1.9 \\
\hline
\end{tabular}

increase in bulk density in the range from $23-28 \%$ and an increase in the degree of impregnation (increase in the weight of the impregnated sample). The coefficient of water absorption as a result of impregnation decreased repeatedly from 7 to 17 times (see table 1). Even when processing with a low-concentrated $\left(\rho=1.17 \mathrm{~g} / \mathrm{cm}^{3}\right)$ calcium polysulfide solution, the water absorption coefficient decreased to a value of $4.5 \%$, an increase in the solution concentration led to a further decrease in the water absorption coefficient to $1.9 \%$.

In experiments on the modification of crushed stone of limestone-shell rock, samples of the Beineu deposit of the Mangistau region were used. To study the effect of the concentration of the impregnating solution on its water absorption, samples of limestone rubble were impregnated with solutions of calcium polysulfide of various densities; the appearance of the original (unimpregnated) gravel and impregnated samples is shown in Fig. 2.
The impregnation was carried out by immersion of samples of crushed stone from limestone-shell rock (fraction 10-20 mm.) in solutions for one hour (see Fig. 2), the results of measuring the bulk density and water absorption coefficient are shown in table 2.

Data given in table 2 show that the impregnation of crushed stone as well as sand in solutions of calcium polysulfide of various densities leads to a significant decrease in the coefficient of water absorption, at the same time, bulk density increases slightly. As a result of impregnation of crushed stone from limestone-shell rock with a solution of calcium polysulfide, the bulk density of crushed stone increased by an average of $2.4 \%$. From table 2 it is also seen that the water absorption of the initial samples is $25.0 \%$, and treatment with a solution with the lowest density equal to $1.17 \mathrm{~g} / \mathrm{cm}^{3}$ leads to a threefold decrease in this parameter, and a parameter value of $8.1 \%$ is achieved. It was found that a gradual

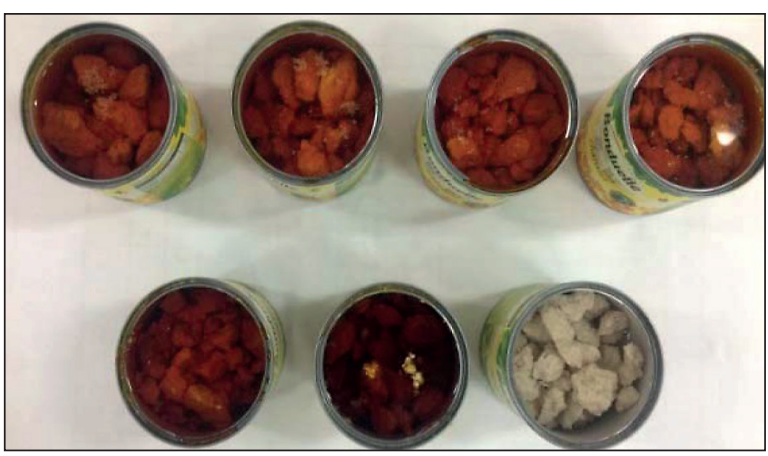

a

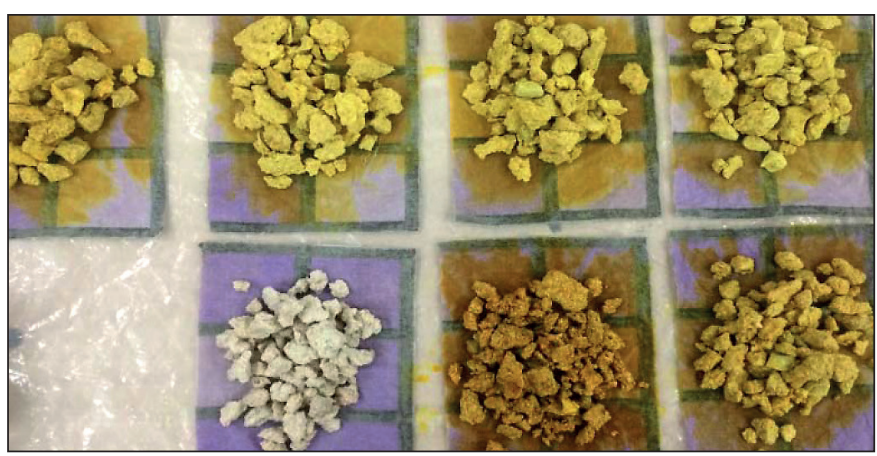

b

Fig. 2. Impregnation of crushed stone samples by immersion in «Aquastat» solutions of various densities in the range from $\rho=1.17 \mathrm{~g} / \mathrm{cm}^{3}$ to $\rho=1.35 \mathrm{~g} / \mathrm{cm}^{3} ; a-$ impregnation of crushed stone samples; $b$ - the appearance of the samples 


\section{MANUFACTURING TECHNOLOGY FOR BUILDING MATERIALS AND PRODUCTS}

Table 2

Dependence of bulk density and coefficient of water absorption of crushed stone on the density of the «Aquastat» impregnating solution

\begin{tabular}{|c|c|c|c|}
\hline № & bulk density $\mathbf{\rho}, \mathbf{g} / \mathbf{c m}^{\mathbf{3}}$ & solution density $\mathbf{\rho}, \mathbf{g} / \mathbf{c m}^{\mathbf{3}}$ & water absorption, $\%$ \\
\hline original & - & 0.675 & 25.0 \\
\hline 1 & 1.17 & 0.685 & 8.1 \\
\hline 2 & 1.19 & 0.697 & 7.9 \\
\hline 3 & 1.20 & 0.679 & 7.5 \\
\hline 4 & 1.22 & 0.686 & 6.5 \\
\hline 5 & 1.24 & 0.682 & 5.2 \\
\hline 6 & 1.35 & 0.691 & 5.2 \\
\hline
\end{tabular}

increase in the density of the impregnating solution leads to a monotonic decrease in the coefficient of water absorption. The smallest value of the parameter of water absorption which equals to $5.2 \%$ belongs to a sample impregnated with a solution of calcium polysulfide with a maximum density of $1.35 \mathrm{~g} / \mathrm{cm}^{3}$. It was found that solution density of $1.24 \mathrm{~g} / \mathrm{cm}^{3}$ is sufficient to reduce the water absorption coefficient to a value of $5.2 \%$, the same as for a density value of $1.35 \mathrm{~g} / \mathrm{cm}^{3}$. The latter is important because it allows for hydrophobization of crushed stone and sand to dispense with solutions of a density of no more than $1.24 \mathrm{~g} / \mathrm{cm}^{3}$, which are much easier to prepare than more concentrated with a density of $1.35 \mathrm{~g} / \mathrm{cm}^{3}$.

It should be noted that traditionally sulfur in construction was used as a melt [18-20], which was used to impregnate building materials. For comparison, the method of hydrophobization with a polysulfide solution and a sulfur melt is shown in Table 3 below, which shows the values of a number of parameters of limestone rubble impregnated under different conditions. The comparison shows a significant increase of 2.1 times the compressive strength during the treatment with sulfur melt, while the treatment with a solution of calcium polysufide leads to an increase in this parameter by 1.36 times. The water absorption of crushed stone during treatment with a solution of calcium polysulfide decreases by 4.6 times, and when treated with a molten sulfur it decreases by 13 times.

But when comparing the effectiveness of the methods used, it is necessary to take into account the difficulties of using a sulfur melt in order to hydrophobize building materials. Impregnation of materials with a sulfur melt includes a number of successive technological processes: heating of sulfur to $150^{\circ} \mathrm{C}$; drying and heating products at a temperature of $130-140^{\circ} \mathrm{C}$; immersion of products in the melt and impregnation; extraction of products from molten sulfur and their cooling. To carry out effective sulfur melt impregnation, it is necessary to use a sealed bath equipped with a vacuum system. As practice has shown, the following disadvantages are also inherent in the method of impregnation of concrete products with a sulfur melt. Firstly,

\section{Table 3}

Dependence of strength and coefficient of water absorption of crushed stone during treatment with calcium polysulfide solution and sulfur melt. Designations in the table: ND - regulatory documents on test methods; 1 - control sample; 2 - processed sample

\begin{tabular}{|c|c|c|c|c|c|}
\hline \multirow[t]{2}{*}{$\begin{array}{l}\text { The name } \\
\text { of indicators }\end{array}$} & \multirow[t]{2}{*}{ ND } & \multicolumn{2}{|c|}{$\begin{array}{c}\text { Solution impregnation Aquastat } \\
\rho=1.24 \mathrm{~g} / \mathrm{cm}^{3}, \text { temperature } 24^{\circ} \mathrm{C}, \\
1 \text { hour }\end{array}$} & \multicolumn{2}{|c|}{$\begin{array}{l}\text { Sulfur melt impregnation } \\
\text { temperature } 160^{\circ} \mathrm{C}, 30 \mathrm{~min}\end{array}$} \\
\hline & & 1 & 2 & 1 & 2 \\
\hline Density, $\mathrm{g} / \mathrm{cm}^{3}$ & GOST 9758 & 792 & 801 & 763 & 842 \\
\hline $\begin{array}{l}\text { The compressive } \\
\text { strength in the cylin- } \\
\text { der, } \mathrm{MPa}\end{array}$ & GOST 9758 & 0.53 & 0.72 & 0.58 & 1.24 \\
\hline Water absorption, $\%$ & GOST 9758 & 24.0 & 5.2 & 28.0 & 2.1 \\
\hline
\end{tabular}


for the implementation of sulfur melt impregnation, it is necessary to heat both sulfur and concrete products to a temperature of $140-150^{\circ} \mathrm{C}$, which significantly increases the energy intensity of the process. In addition, heating products to such temperatures can cause stresses in the material and lead to a decrease in strength. Secondly, due to the relatively high viscosity of the sulfur melt, it is necessary to use evacuation or overpressure, which greatly complicates and increases the cost of sulfur melt impregnation technology.

It should also be noted that the process is sensitive to temperature fluctuations, since sulfur is liquid only in a certain temperature range. Therefore, in spite of a marked improvement in the characteristics (water absorption, frost resistance, mechanical strength, chemical resistance) of sulfur-impregnated concrete, this method was not widely used, even despite the environmental safety of the impregnated products. The disadvantage in this method is the difficulty of impregnation from the molten state. Currently, products impregnated with molten sulfur are used in special cases when it is necessary to protect concrete from aggressive environments (acidic environments and saline solutions) [21-22].

\section{FINDINGS}

1. Research data on the efficiency of impregnation with polysulfide solutions of sand and gravel formed during the development of limestone-shell rock deposits and their use in road dumping have been presented. As in earlier studies, impregnation allows polysulfide molecules to penetrate into the pore structure of limestone-limestone and, when the material dries, sulfur nanoparticles crystallize from its polysulfide solution in its pores, partially filling the pore space and forming a protective, durable, insoluble hydrophobic coating that impedes the penetration of water into the shell pores.

2. As a result of sand impregnation, the water absorption coefficient drastically decreases from 7 to 17 times, the water absorption coefficient decreases from $32.5 \%$ for the initial to $1.9 \%$ impregnated. Even when treated with a weakly concentrated $\left(\rho=1.17 \mathrm{~g} / \mathrm{cm}^{3}\right)$ calcium polysulfide solution, the water absorption coefficient decreased to a value of $4.5 \%$.

3. As a result of impregnation of crushed stone from limestone-limestone with a solution of calcium polysulfide, the coefficient of water absorption decreases from $25.0 \%$ for untreated to $5.2 \%$ for treated, and the decrease in the coefficient of water absorption is greater for concentrated solutions. It was found that a solution density of $1.24 \mathrm{~g} / \mathrm{cm}^{3}$ is sufficient to reduce the water absorption coefficient to a value of $5.2 \%$, the same as for a density value of $1.35 \mathrm{~g} / \mathrm{cm}^{3}$.

4. Comparison of the results of impregnation with «Aquastat» solution and sulfur melt showed that as a result of treatment with sulfur melt, the water absorption coefficient decreases by 13.3 and strength increases by 2 times, and as a result of impregnation with «Aquastat» solution decreases by $4.62 \%$, strength increases by 1.35 times. Despite the high efficiency of sulfur melt processing, such treatment has drawbacks associated with the use of autoclave technology and elevated temperatures.

5 . The results of the modification of sand and crushed stone from shell rock by impregnating it with «Aquastat» solution, a significant decrease in the parameter of water absorption, increased compressive strength, revealed the possibility of using impregnated crushed stone as the layer material lying in the base of road structures of local roads in the form of crushed stone and sand instead of more expensive imported rubble.

\section{REFERENCES}

1. Hambartsumyan N.V. Building rocks for the production of wall and facing materials. Moscow, MGI, 1982. 282 p. (In Russian).

2. Sementovsky Yu.V. Facing stones: Reference book. Scientific. ed. A.S. Filko; Ministry of nature resources of the Russian Federation. Moscow, Geoinformmark, 1998, 25 p. (In Russian).

3. Sementovsky Yu.V. Limestone: Reference book. Scientific. ed. A.S. Filko; Ministry nature resources of the Russian Federation. Moscow, Geoinformmark, 1999, 19 p. (In Russian).

4. Mountain Encyclopedia. Ch. ed. E.A. Kozlovsky; Editors: M.I. Agoshkov, N.K. Baibakov, A.S. Boldyrev et al. Moscow, Sov. Encyclopedia, 1985, V. 2, 575 p. (In Russian).

5. Bakka N.T., Ilchenko N.T. Facing stone. Geological, industrial and technological assessment of deposits: Reference book. Moscow, Nedra, 1992, 303 p. (In Russian).

6. Natural facing stones of Kazakhstan: reference book. Ed. A.A. Abdullina, H.A. Bespayeva, E.S. Votsalevsky, S.Zh. Daukeeva, L.A. Miroshnichenko. Almaty: Information-analytical center of geology and mineral resources of the Republic of Kazakhstan. (In Russian). 
7. Bazhenov Yu.M. Concrete Polymers. Moscow, Stroyizdat, 1983. 472 p. (In Russian).

8. Ramachandran V., Feldman R., Baudouin J. The science of concrete. Physico-chemical concrete science. Per. from English Under the editorship of V.B. Moscow, Stroyizdat, 1986, 278 p. (In Russian).

9. Pokrovsky N.S. Impregnating concrete waterproofing. Moscow, Energy. 1964, 112 p. (In Russian).

10. Massalimov I.A., Chuykin A.E., Massalimov B.I., Urakaev F.H., Uralbekov B.M., Burkitbaev M.M. Improvement of operational properties of shell limestone building materials by polysulfide solution impregnation. Nanotechnologies in Construction. 2017, Vol. 9, no. 3, pp. 66-80. DOI: dx.doi.org/10.15828/2075-8545-2017-9-3-66-80. (In Russian).

11. Massalimov I.A., Chuykin A.E., Massalimov B.I., Urakaev F.H., Uralbekov B.M., Burkitbaev M.M. Improvement of operational properties of shell limestone building materials by polysulfide solution impregnation. Nanotechnologies in Construction. 2017, Vol. 9, no. 3, pp. 66-80. DOI: dx.doi.org/10.15828/2075-8545-2017-9-3-66-80. (In Russian).

12. Yanakhmetov M.R., Chuykin A.E., Massalimov I.A. Pore structure modification of cement concretes by impregnation with sulfur-containing compounds. Nanotechnologies in Construction. 2015, Vol. 7, no. 1, pp. 63-72. DOI: dx.doi.org/10.15828/20758545-2015-7-1-63-72.

13. Yanakhmetov M.R., Chuykin A.E., Massalimov I.A. Pore structure modification of cement concretes by impregnation with sulfur-containing compounds. Nanotechnologies in Construction. 2015, Vol. 7, no. 1, pp. 63-72. DOI: dx.doi.org/10.15828/20758545-2015-7-1-63-72.

14. Massalimov I.A., Yanakhmetov M.R., Chuykin A.E., Massalimov B.I., Urakaev F.H., Uralbekov B.M., Burkitbaev M.M. Hydrophobization of dense and fine concrete by polysulfide solutions. Nanotechnologies in Construction. 2016, Vol. 8, no. 5, pp. 85-99. DOI: dx.doi.org/10.15828/2075-8545-2016-8-5-85-99. (In Russian).

15. Massalimov I.A., Yanakhmetov M.R., Chuykin A.E., Mustafin A.G. Protection of Building Constructions with Sulfur Impregnating Solution. Study of Civil Engineering and Architecture (SCEA). June 2013. Vol. 2. Issue 2. pp. 19-24.

16. Massalimov I.A., Yanakhmetov R.R., Chuikin A.E., Khusainov A.N., Mustafin A.G. The method of processing building materials with polysulfide solutions. Patent 024383 Eurasian, C04B 41/50. C04B 28/36 / No. 201400277; declared 03/26/2014; publ. 09/30/2016. Bull. No. 9. 5 p. (In Russian).

17. M.R. Yanakhmetov, I.A. Massalimov, A.E. Chuykin, A.N. Khusainov, A.G. Mustafin Transformation of polysulfide molecules into nanosized sulfur particles in porous inorganic systems. Bulletin of the Bashkir University. 2013. V. 18. No. 3. pp. 691-693 (In Russian).

18. Paturoev V.V., Volgushev A.M., Orlovsky Yu.I. Sulfuric and sulfur impregnated concrete. Review inf. Moscow, VNIIS Gosstroy of the USSR, 1985. Ser. 7. Issue 1. 59 p. (In Russian).

19. Paturoev V.V., Orlovsky Yu.I., Manzai V.P. Technology of impregnation of concrete products with molten sulfur. Concrete and reinforced concrete. 1983, no. 7, pp. 28-29. (In Russian).

20. Milica M. Vlahovic, Sanja P. Martinovic, Tamara Dj. Boljanac, Predrag B. Jovanic, Tatjana D. Volkov-Husovic. Durability of sulfur concrete in various aggressive environments. Construction and Building Materials. Vol. 25, Issue 10, October 2011, Pp. 3926-3934. https://doi.org/10.1016/j.conbuildmat.2011.04.024.

21. Mc Bee W.C, Sullivan T.A, Jong B.W. Industrial evaluation of sulfur concrete in corrosive environments. Bu Mines RI 8786; 1983. p. 15.

22. Margareth Dugarte, Gilberto Martinez-Arguelles and Jaime Torres Experimental Evaluation of Modified Sulfur Concrete for Achieving Sustainability in Industry Applications. Sustainability 2019, v. 11, No. 70, pp. 1-16. DOI:10.3390/su11010070. 


\section{INFORMATION ABOUT THE AUTHORS}

Ismail A. Massalimov, Doctor of Technical Sciences, Professor, Bashkir State University; Head of Laboratory, Research Technological Institute of Herbicides of the Academy of Sciences of the Republic of Bashkortostan (GBU NITIG AN RB); st. Ulyanov d.65, Ufa, 450029; Ltd IC «SULFIDE TECHNOLOGIES»; ismail_mass@mail.ru;

Burkhan I. Massalimov, Engineer, Physics Institute. P.N. Lebedev RAS; Leninsky Prospekt, 63, Moscow, 119991; Ltd IC «SULFIDE TECHNOLOGIES» b.massalimov@yandex.ru;

Bulat S. Ahmetshin, Assistant FSBEI HE BashGU; st. Zaki Validi 32, 450076, Ufa; Ltd IC «SULFIDE TECHNOLOGIES», akhbulat @ mail;

Farit K. Urakaev, Doctor of Chemical Sciences, Leading Researcher, V.S. Institute of Geology and Mineralogy Sobolev SB RAS; Akademika Koptyug Avenue, 3, Novosibirsk, 630090, urakaev@igm.nsc.ru;

Mukhambetkali M. Burkitbaev, Doctor of Chemical Sciences, Vice Rector, Kazakh National University. al-Farabi; al-Farabi avenue, 71, Kazakhstan, Almaty, 050040; mukhambetkali.Burkitbayev@kaznu.kz 